\title{
Competitive Adsorption of Metals onto Magnetic Graphene Oxide: Comparison with Other Carbonaceous Adsorbents
}

\author{
Jin Hur, ${ }^{1}$ Jaewon Shin, ${ }^{1}$ Jeseung Yoo, ${ }^{2}$ and Young-Soo Seo ${ }^{2}$ \\ ${ }^{1}$ Department of Environment \& Energy, Sejong University, Seoul 143-747, Republic of Korea \\ ${ }^{2}$ Department of Nano Science \& Technology, Sejong University, Seoul 143-747, Republic of Korea \\ Correspondence should be addressed to Jin Hur; jinhur@sejong.ac.kr
}

Received 7 November 2014; Revised 14 January 2015; Accepted 20 January 2015

Academic Editor: Guangliang Liu

Copyright (c) 2015 Jin Hur et al. This is an open access article distributed under the Creative Commons Attribution License, which permits unrestricted use, distribution, and reproduction in any medium, provided the original work is properly cited.

\begin{abstract}
Competitive adsorption isotherms of $\mathrm{Cu}(\mathrm{II}), \mathrm{Pb}(\mathrm{II})$, and $\mathrm{Cd}(\mathrm{II})$ were examined on a magnetic graphene oxide (GO), multiwalled carbon nanotubes (MWCNTs), and powered activated carbon (PAC). A series of analyses confirmed the successful synthesis of the magnetic GO based on a simple ultrasonification method. Irrespective of the adsorbents, the adsorption was highly dependent on $\mathrm{pH}$, and the adsorption was well described by the Langmuir isotherm model. The maximum adsorption capacities of the adsorbents were generally higher in the order of $\mathrm{Pb}(\mathrm{II})>\mathrm{Cu}(\mathrm{II})>\mathrm{Cd}(\mathrm{II})$, which is the same as the degree of the electronegativity and the hydrated radius of the metals, suggesting that the metal adsorption may be governed by an ion exchange between positively charged metals and negatively charged surfaces, as well as diffusion of metals into the surface layer. The adsorption of each metal was mostly lower for multi- versus single-metal systems. The antagonistic effects were influenced by solution $\mathrm{pH}$ as well as the type of metals, and they were higher in the order of the magnetic GO > MWCNT > PAC. Dissolved HS played a greater role than HS adsorbed onto the adsorbents, competing with the adsorption sites for metal complexation.
\end{abstract}

\section{Introduction}

Due to growing industrialization and urbanization, heavy metals are increasingly introduced into aquatic environments via various pathways. Heavy metals are not bioavailable and tend to accumulate in living tissues, thereby threatening human health and aquatic ecosystems. A variety of the treatment technologies have been proposed and used to eliminate heavy metals from polluted water. Such technologies are mostly based on adsorption, chemical precipitation, ion exchange, membrane filtration, reverse osmosis, and electrolysis [1]. Among those, adsorption can be ranked as one of the most preferred methods for treating heavy metals because of its high efficiency in the cost and the operation. The choice of adsorbents is the key to successful application for the adsorption-based treatments. Activated carbon, inorganic minerals, and bioadsorbents have been studied as popularly used adsorbents [1]. Recently, carbon nanotubes (CNTs) and graphene materials emerged as promising adsorbents for heavy metal removal because of their high specific surface areas and chemically stable structures $[2,3]$.
Graphene oxide (GO), prepared by oxidation of natural graphite, is a two-dimensional nanomaterial bearing several functional groups such as hydroxyl, epoxide, carbonyl, and carboxyl groups on its basal planes and sheet edges [4]. The large surface area and the abundance of the oxygencontaining functional groups make GO highly attractive for the removal of heavy metals from polluted water. However, good dispersive property of GO in aqueous phases has been regarded as an obstacle for separating and retrieving the adsorbent for reuse after treating heavy metals. Recently, combining graphene with the magnetic materials such as $\mathrm{Fe}_{3} \mathrm{O}_{4}$ was suggested to overcome this limitation $[3,5-12]$. Furthermore, $\mathrm{Fe}_{3} \mathrm{O}_{4}$ is known to have low toxicity and good biocompatibility, which is advantageous for water treatment in practice [13].

In many cases, the removal efficiency of adsorbents is evaluated based on the adsorption capacity for a single-metal system, which contrasts with the common observation of the industrial wastewater or other polluted water sources containing a mixture of several heavy metals. Therefore, it is desirable for the full applications in practice to examine 
the adsorption behavior of the individual metals under multimetal systems, in which more than two types of metals exist together and they might compete with each other for the same adsorption sites. A comparison between singleand multimetal systems for the adsorption performance can ultimately provide a guideline for choosing the most feasible adsorbents for the water contaminated with a mixture of heavy metals, as well as for seeking the optimum operating conditions.

The adsorption of metals onto activated carbon $(\mathrm{AC})$ and CNTs, which have been frequently studied for the removal of heavy metals, is well documented $[2,14]$. It was reported that acidic functional groups distributed on the adsorbent's surfaces play critical roles in binding metals through ion exchange, electrostatic attraction, and sorption-precipitation processes [2]. Magnetic GO is recently highlighted as an effective adsorbent for treating heavy metals, while further investigation is required to warrant the widespread use in practice [9]. There are only limited adsorption studies using magnetic GO for multimetal systems [15]. A few studies have attempted to compare several adsorbents including GO for their metal adsorptive capabilities [10, 15]. However, they simply adopted the results from other studies to highlight the advantages of their own materials without a rigorous comparison based on the experiments. It is noteworthy that the adsorption performances of different adsorbents should be compared under the same experimental conditions in order to provide the exact information on the metal selectivity and adsorption affinities. The objectives of this study are (1) to compare the adsorption behaviors of $\mathrm{Cu}(\mathrm{II}), \mathrm{Pb}(\mathrm{II})$, and $\mathrm{Cd}$ (II) for three different carbonaceous materials (i.e., AC, CNT, and magnetic GO) under the identical experimental condition and (2) to explore the competitive adsorption behaviors of the metals on each adsorbent by comparing the adsorption behaviors between single- and multimetal systems.

\section{Material and Methods}

2.1. Preparation of Graphite Oxide. Graphite oxide was prepared based on a modification of the Hummers method using graphite flakes [16]. For pretreatment, $12 \mathrm{~g}$ of graphite flakes (Aldrich) was added into $50 \mathrm{~mL}$ of a preheated sulfuric acid $\left(\mathrm{H}_{2} \mathrm{SO}_{4}\right)$ solution containing $10 \mathrm{~g}$ each of potassium persulfate $\left(\mathrm{K}_{2} \mathrm{~S}_{2} \mathrm{O}_{8}\right.$, Sigma-Aldrich) and phosphorus pentoxide $\left(\mathrm{P}_{2} \mathrm{O}_{5}\right.$, Sigma-Aldrich). They were mixed at $80^{\circ} \mathrm{C}$ for 5 hours. The mixture was left at room temperature overnight after $2 \mathrm{~L}$ of Milli-Q water was added. The pretreatment was completed by filtering the mixture through $5 \mu \mathrm{m}$ pore-sized filters (polyester fiber). For further treatment, $2 \mathrm{~g}$ of the purified graphite, $2 \mathrm{~g}$ of $\mathrm{NaNO}_{3}$, and $46 \mathrm{~mL}$ of sulfuric acid were mixed together in a flask in an ice bath below $10^{\circ} \mathrm{C}$. $6 \mathrm{~g}$ of $\mathrm{KMnO}_{4}$ (Sigma-Aldrich) was added, slowly mixed, and left for reaction in a water bath at $35^{\circ} \mathrm{C}$ for 2 hours before $92 \mathrm{~mL}$ of Milli-Q water was slowly added. The solution was then mixed with $280 \mathrm{~mL}$ of Milli-Q water and $8 \mathrm{~mL}$ of $\mathrm{H}_{2} \mathrm{O}_{2}(30 \%)$ until the color turned yellow. The supernatant was decanted, and the remaining solution was centrifuged at
3,000 rpm for 1 hour. The solid phase was rinsed with $4 \mathrm{M} \mathrm{HCl}$ solution $(200 \mathrm{~mL})$ for the final purification of graphite oxide. Additional treatment (i.e., sonification in Milli-Q water for 1 hour) was applied to obtain bare GO.

2.2. Magnetic GO Synthesis. $\mathrm{Fe}_{3} \mathrm{O}_{4}$ nanoparticles were prepared following a procedure previously reported in Wei and Wang [17]. In this study, magnetic GO was synthesized by mixing $0.05 \mathrm{~g}$ of $\mathrm{Fe}_{3} \mathrm{O}_{4}$ nanoparticles with the prepared graphite oxide having several stacked layers at a mass ratio of 9:1 in Milli-Q water followed by ultrasonication of the mixture solution for 20 minutes, where $\mathrm{Fe}_{3} \mathrm{O}_{4}$ nanoparticles are tightly attached to $\mathrm{GO}$ via nonspecific interaction rather than chemical pathways. Detailed procedure will be reported elsewhere. The solution was finally freeze-dried, and the remaining solids were used as a magnetic GO for the subsequent adsorption experiments. The synthesis of magnetic GO was confirmed by scanning electron microscopy (SEM, HITACHI S-4700), transmission electron microscopy (TEM, $200 \mathrm{kV}$ FE-TEM-JEOL), X-ray diffraction (XRD, D/MAX2500/PC, Rigaku), Raman spectroscopy (Renishaw 633 nm), and Fourier transform infrared spectroscopy (FT-IR, PerkinElmer spectrum 100).

2.3. Adsorption Experiments. Multiwalled CNT (MWCNT) and powdered activated carbon (PAC) were purchased from a supplier (Sigma-Aldrich) as the comparative adsorbents for our magnetic GO. The points of zero charge $\left(\mathrm{pH}_{\mathrm{PZC}}\right)$ values of all the adsorbents were estimated following an acid-base titration method suggested by Li et al. [3].

Three divalent metals $\mathrm{Cu}(\mathrm{II}), \mathrm{Pb}(\mathrm{II})$, and $\mathrm{Cd}(\mathrm{II})$ were used for the adsorbates. The three metals were all prepared in nitrate stock solutions at $1000 \mathrm{mg} / \mathrm{L}$. Suwannee River fulvic acid (SRFA), which is a representative aquatic humic substance, was obtained from the International Humic Substance Society to examine influence of fulvic acids $(10 \mathrm{mg} / \mathrm{L})$ on the metal adsorption.

Batch adsorption experiments were conducted in triplicate by mixing each metal in a range of concentrations into $0.01 \mathrm{NaNO}_{3}$ solution containing $0.4 \mathrm{~g} \mathrm{~L}^{-1}$ of the adsorbents (i.e., magnetic GO, MWCNT, and PAC). Adsorption was done by mixing the suspension solutions in a shaker at $150 \mathrm{rpm}$ for 24 hours at a room temperature of $20 \pm 1^{\circ} \mathrm{C}$. The mixing time was chosen as an apparent equilibrium time for this study based on previous reports using GO $[10,18]$. Different $\mathrm{pH}$ values were achieved to examine the solution $\mathrm{pH}$ effects on adsorption behaviors by adding $0.1 \mathrm{~N} \mathrm{HCl}$ or $0.1 \mathrm{~N} \mathrm{NaOH}$ solution with the maximum added volume maintained below $1 \%$ of the total volume. Competitive adsorption was evaluated by comparing the adsorption results for a single metal versus a mixture of three metals. After equilibrium, the supernatants were separated by filtering the solution through the $0.22 \mu \mathrm{m}$ membrane filter (cellulose acetate) prewashed with the samples. The concentrations of the metals in the filtrates were determined on ICP-OES (iCAP6300 Duo, Thermo, UK). Dissolved organic carbon (DOC) concentrations of SRFA were measured using a Shimadzu V-CPH analyzer. The adsorption amounts of 


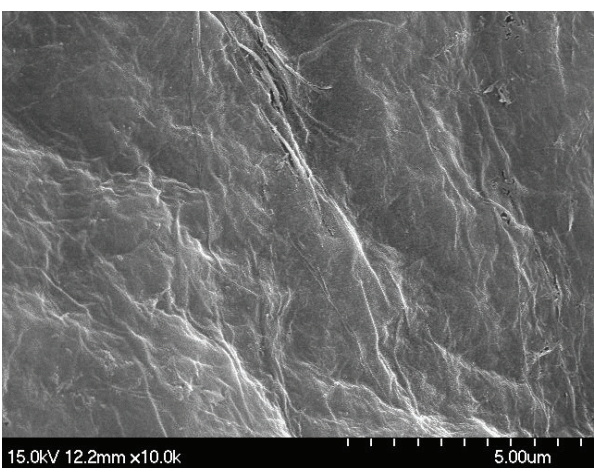

(a)

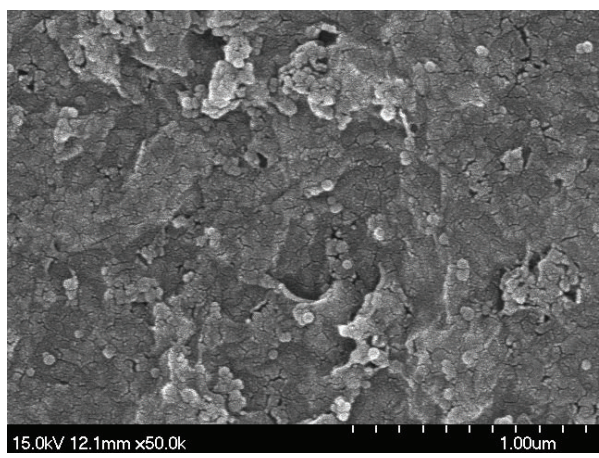

(c)

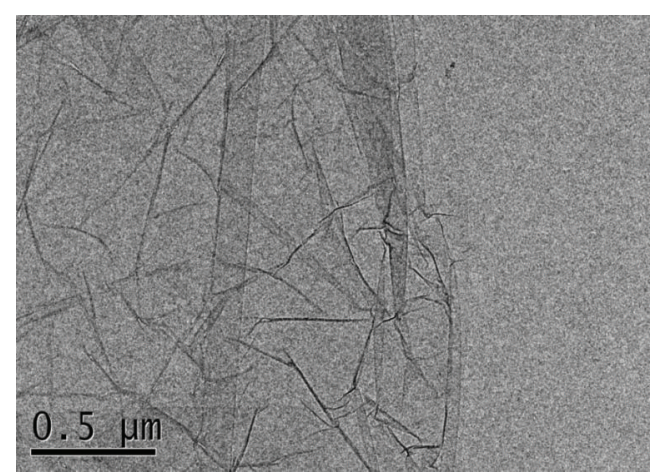

(b)

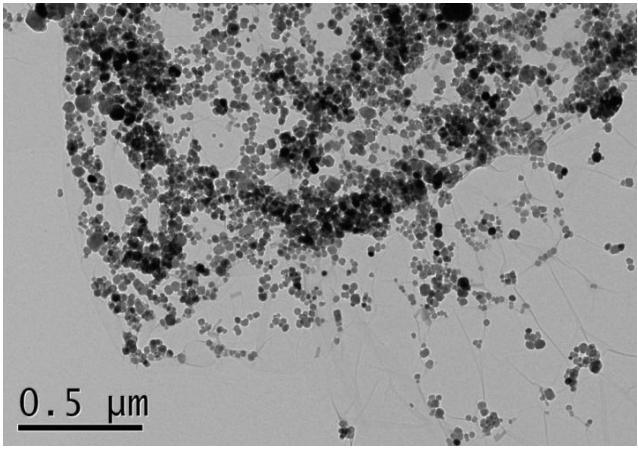

(d)

FIGURE 1: SEM (a) and TEM (b) images of the bare GO for this study. SEM (c) and TEM (d) images of the magnetic GO synthesized in this study.

either metal or SRFA on the adsorbents were calculated by the difference between the initial added concentrations and the corresponding residual amount after adsorption.

The adsorption data were fitted by the Langmuir (1) and Freundlich (2) models, and the related isotherm parameters were estimated:

$$
\begin{gathered}
q_{e}=\frac{q_{\max } \cdot k_{L} \cdot C_{e}}{1+k_{L} \cdot C_{e}} \\
q_{e}=k_{F} \cdot C_{e}^{1 / n}
\end{gathered}
$$

where $q_{e}\left(\mathrm{mgg}^{-1}\right)$ and $q_{\max }\left(\mathrm{mg} \mathrm{g}^{-1}\right)$ are the equilibrium adsorption amount and the maximum adsorption capacity, respectively, and $C_{e}\left(\mathrm{mg} \mathrm{L}^{-1}\right)$ is the equilibrium metal concentration in solution. $k_{L}\left(\mathrm{~L} \mathrm{mg}^{-1}\right)$ is the adsorption affinity related to adsorption energy; $k_{F}$ and $1 / n$ are the Freundlich model capacity factor and the Freundlich model site heterogeneity factor, an indicator of isotherm nonlinearity, respectively.

\section{Results and Discussion}

3.1. Characterization of Magnetic GO. Comparison of the SEM and the TEM images between the bare GO and the magnetic $\mathrm{GO}$ revealed that $\mathrm{Fe}_{3} \mathrm{O}_{4}$ nanoparticles were successfully attached to the GO surfaces without the damage of the layered structures during the synthesis (Figure 1). The XRD patterns of $\mathrm{GO}, \mathrm{Fe}_{3} \mathrm{O}_{4}$ nanoparticles, and the magnetic $\mathrm{GO}$ are displayed in Figure 2(a). The diffraction peaks of the $\mathrm{GO} / \mathrm{Fe}_{3} \mathrm{O}_{4}$ composite are characterized by a combination of the individual peak patterns of $\mathrm{GO}$ and $\mathrm{Fe}_{3} \mathrm{O}_{4}$. For example, a unique peak of the bare GO appearing at $2 \theta=12.1^{\circ}$ was also shown for the peak pattern of the magnetic GO, and the other peaks of the magnetic GO appearing at $2 \theta=30.2^{\circ}, 35.5^{\circ}$, $43.2^{\circ}, 53.7^{\circ}$, and $62.8^{\circ}$ corresponded to those of the $\mathrm{Fe}_{3} \mathrm{O}_{4}$ nanoparticles. Our XRD results also indicate the successful composition of $\mathrm{GO}$ and $\mathrm{Fe}_{3} \mathrm{O}_{4}$, consistent with previous reports $[5,10,19]$, in which ordered graphitic crystal structures of GO still remained after the functionalized processes with $\mathrm{Fe}_{3} \mathrm{O}_{4}$ nanoparticles. The Raman spectrum of the bare GO is characterized by two well-defined peaks at $1321 \mathrm{~cm}^{-1}$ and $1604 \mathrm{~cm}^{-1}$, each of which corresponds to disordered (D band) and ordered ( $G$ band) crystal structures of carbon [5]. The same peaks were found for our magnetic GO with the peaks of $\mathrm{Fe}_{3} \mathrm{O}_{4}$ partly superimposed (Figure 2(b)). The FT-IR spectra of the bare GO and the magnetic GO also confirmed the successful composition (Figure 2(c)). The spectrum of the magnetic GO consists of a unique peak of $\mathrm{Fe}_{3} \mathrm{O}_{4}$ at $570 \mathrm{~cm}^{-1}$, corresponding to the stretching vibration of $\mathrm{Fe}-\mathrm{O}$, and several weakened and/or split peaks of the bare GO, which include a broad peak at $3328 \mathrm{~cm}^{-1}$ (stretching of $\mathrm{O}-\mathrm{H}$ ), $1605 \mathrm{~cm}^{-1}$ (stretching of $\mathrm{C}=\mathrm{C}$ ), $1405 \mathrm{~cm}^{-1}$ (shifted stretching of $\mathrm{C}=\mathrm{O}$ ), and $1120 \mathrm{~cm}^{-1}$ (stretching of $\mathrm{C}-\mathrm{OH}$ and the deformation of the $\mathrm{C}-\mathrm{O}$ band) [5]. 


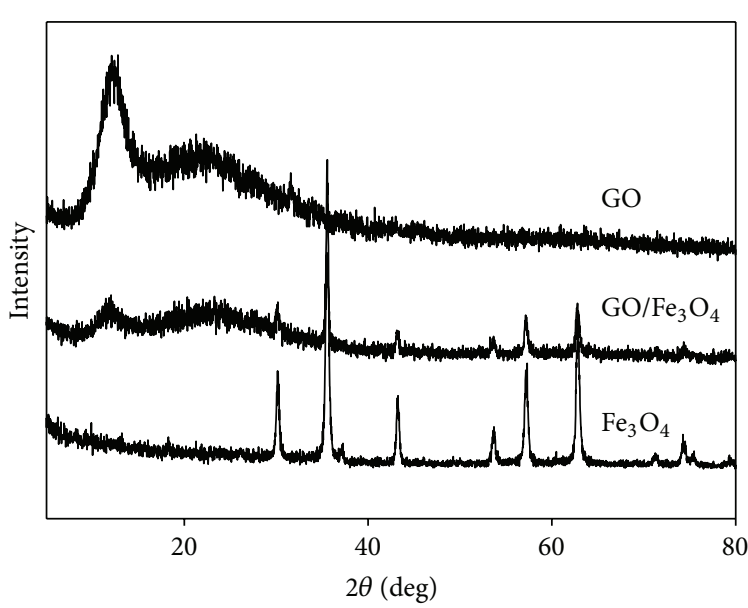

(a)

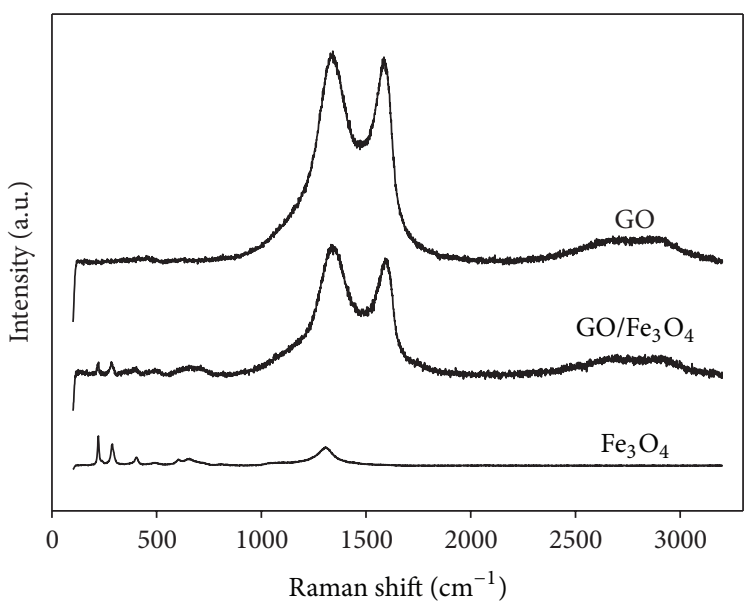

(b)

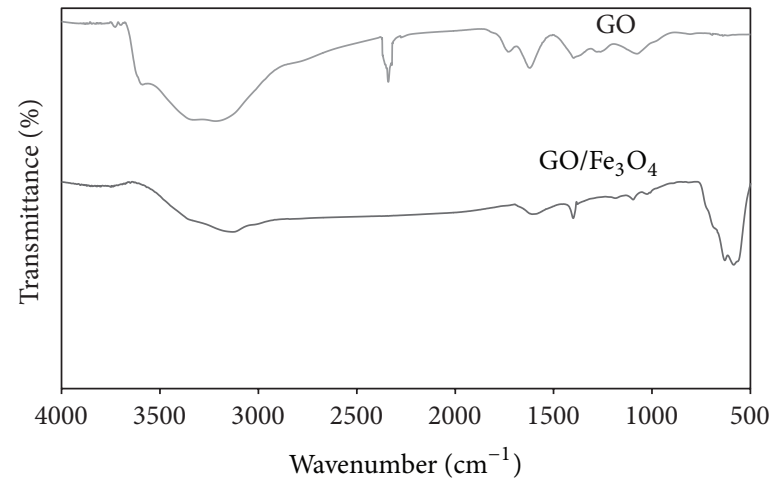

(c)

FIgURE 2: The XRD patterns (a), the Raman spectra (b), and the FT-IR spectra (c) of bare GO, the magnetic $\mathrm{GO}\left(\mathrm{GO} / \mathrm{Fe}_{3} \mathrm{O}_{4}\right)$, and $\mathrm{Fe} \mathrm{O}_{3}$.

Based on acid-base titration curves (see Figure S1 in Supplementary Material available online at http://dx.doi.org/ $10.1155 / 2015 / 836287)$, the $\mathrm{pH}_{\text {PZC }}$ values of the adsorbents were estimated to be 4.5, 5.0, and 6.6 for the magnetic GO, MWCNT, and PAC, respectively. The $\mathrm{pH}_{\mathrm{ZPC}}$ value of the magnetic GO corresponds to a middle point between the reported values of the bare $\mathrm{GO}$ and magnetite (i.e., $\mathrm{Fe}_{3} \mathrm{O}_{4}$ ) $[20,21]$. The BET surface area of the magnetic GO was $49.9 \mathrm{~m}^{2} / \mathrm{g}$, while those of MWCNT and PAC are reported to be $220 \mathrm{~m}^{2} / \mathrm{g}$ (from supplier) and $886 \mathrm{~m}^{2} / \mathrm{g}$ [22], respectively.

3.2. Influence of $p H$ on Metal Removal by Adsorption. The effects of solution $\mathrm{pH}$ on the percent removal were compared for the types of the metals and the adsorbents in Figure 3. For all cases, the percent removal increased with a higher $\mathrm{pH}$, and a sharp increase was found at the $\mathrm{pH}$ ranges around the $\mathrm{pH}_{\mathrm{PZC}}$ value of each adsorbent. At $\mathrm{pH}<\mathrm{pH}_{\mathrm{ZPC}}$, the surfaces of the adsorbents are net positively charged due to the protonation of the acidic functional groups attached to carbon structures. The low adsorption levels at the lower $\mathrm{pH}$ ranges can be thus attributed to electrostatic repulsion between the net positively charged surfaces and the predominant metal species with a positive charge (i.e., $\mathrm{Cu}^{2+}, \mathrm{Cd}^{2+}$, and $\mathrm{Pb}^{2+}$ )
(Figure S2) and also to stronger competition between $\mathrm{H}^{+}$ and the metal ions for the available adsorption sites [23, 24]. At $\mathrm{pH}>\mathrm{pH}_{\mathrm{ZPC}}$, in contrast, the deprotonated sites on the surfaces become expanded with a higher $\mathrm{pH}$, resulting in stronger attraction for positively charged metal ions present in the solution. The high level of adsorption at the higher $\mathrm{pH}$ ranges can also be driven by the precipitation of insoluble metal species on the surfaces and by surface ligand exchange of negatively charged metal species [3].

Despite the similar trends with $\mathrm{pH}$, the individual responses of each metal adsorption to solution $\mathrm{pH}$ were different depending on the types of the metals as well as the adsorbents (Figure 3). For example, a higher removal was accomplished by adsorption in the order of $\mathrm{Pb}$ (II) $>\mathrm{Cu}$ (II) $>\mathrm{Cd}(\mathrm{II})$ for the magnetic $\mathrm{GO}$ at the $\mathrm{pH}$ around $\mathrm{pH}_{\mathrm{PZC}}$, while the higher adsorption level of $\mathrm{Pb}$ (II) versus $\mathrm{Cu}$ (II) was not found for the other two adsorbents in the similar $\mathrm{pH}$ range (Figure 3). In addition, it was observed that the relative differences in the percent removal between the three metals were not the same for the different adsorbents at a particular $\mathrm{pH}$. The slight decrease in adsorption of $\mathrm{Pb}(\mathrm{II})$ on MWCNT and $\mathrm{PAC}$ at very high $\mathrm{pH}$ ranges is possibly explained by the formation of negatively charged hydroxide complexes such as $\mathrm{Pb}(\mathrm{OH})_{3}{ }^{-}$(Figure $\mathrm{S} 2$ ). 


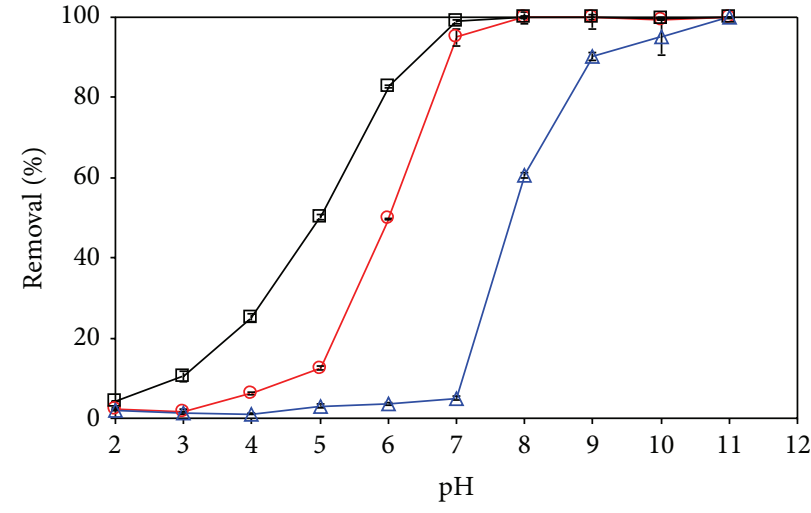

(a)

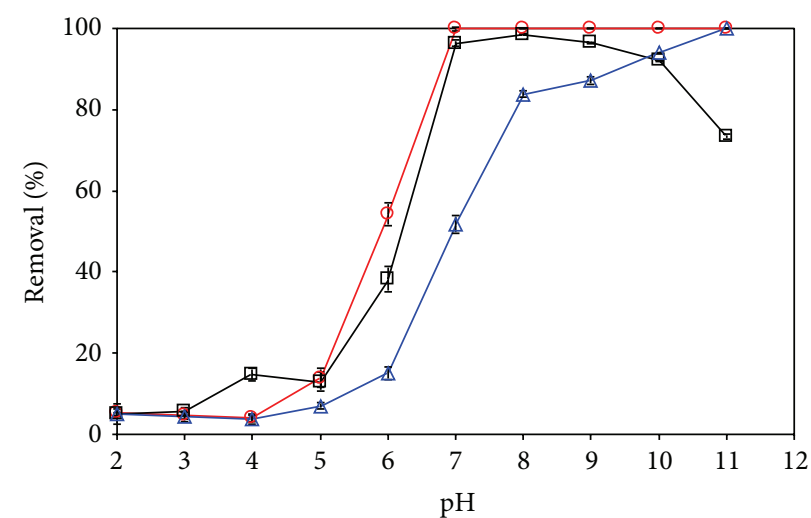

(b)

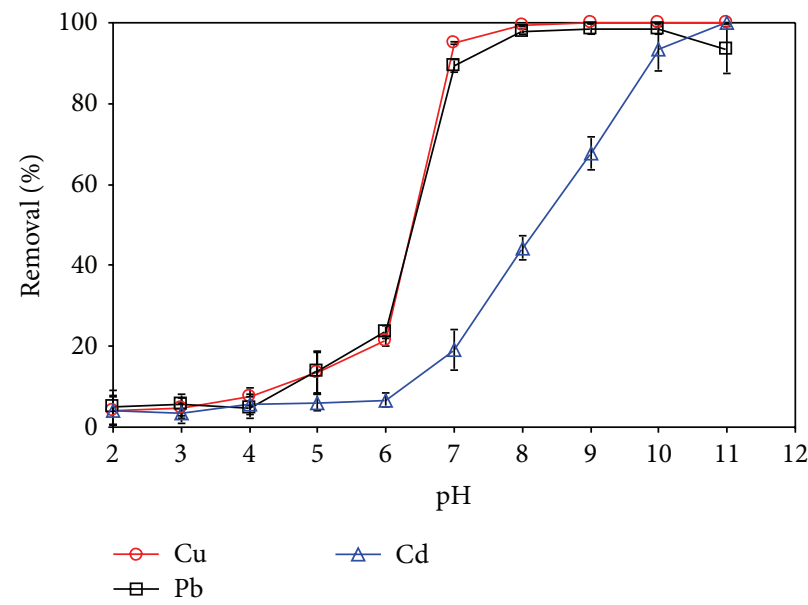

(c)

FIGURE 3: Effects of solution $\mathrm{pH}$ on the percent removals of three metals by adsorption upon magnetic GO (a), MWCNT (b), and PAC (c).

3.3. Adsorption Isotherms on Magnetic GO for Single-Metal Systems. Equilibrium adsorption isotherms on the magnetic $\mathrm{GO}$ and the associated model parameters were compared for the three metals at different $\mathrm{pH}(4.0,6.0$, and 7.0) (Figure 4 and Table 1). Mostly, the Langmuir isotherm model fitted better the experimental data than the Freundlich model as revealed by the higher $R^{2}$ values $\left(R^{2}=0.963\right.$ to 0.999$)$, suggesting that the metal adsorption could be described by a monolayer adsorption process [9]. For all the $\mathrm{pH}$ conditions, the $q_{\max }$ values of the magnetic GO were higher for the metals in the order of $\mathrm{Pb}$ (II) $>\mathrm{Cu}$ (II) $>\mathrm{Cd}$ (II), which were $15.48 \pm 0.95,6.24 \pm 0.21$, and $1.28 \pm 0.03 \mathrm{mg} \mathrm{g}^{-1}$ at $\mathrm{pH} 4.0$, $38.50 \pm 3.16,23.09 \pm 1.45$, and $4.41 \pm 0.19 \mathrm{mg} / \mathrm{g}$ at $\mathrm{pH} 6.0$, and $81.49 \pm 9.94,59.44 \pm 3.64$, and $9.92 \pm 0.55 \mathrm{mgg}^{-1}$ at pH 7.0 (Table 1). The relative order of the $q_{\max }$ values agreed well with previous adsorption studies using MWCNT [23], peat [25], and magnetic GO [9]. Again, the increased metal adsorption at a higher $\mathrm{pH}$ can be attributed to the weakened competition between $\mathrm{H}^{+}$and the positively charged metals for the adsorption sites (i.e., acidic functional groups) as well as to the decrease in the positive surface charge resulting in a lower degree of the electrostatic repulsion between the metals and the adsorbent. The $q_{\max }$ values of this study were compared with those recently reported with magnetic GO (Table 2). The values were comparable to the range previously reported.

It is noteworthy that the order of the $q_{\max }$ values is the same as that of the electronegativity of the metals, which are $2.33,1.90$, and 1.69 for $\mathrm{Pb}(\mathrm{II}), \mathrm{Cu}(\mathrm{II})$, and $\mathrm{Cd}(\mathrm{II})$, respectively [26]. This result strongly suggests that ion exchange may be a dominant mechanism to explain the metal adsorption. Diffusion may also operate as an important factor for the adsorption, controlling the transfer of metals to the adsorbent's surface [27]. In this case, smaller sized metals can easily penetrate into the boundary layers and/or the pores of the adsorbents, subsequently occupying more available sites. In this study, the adsorption levels of the metals were consistent with the decreasing order of the radii of the hydrated metals (Pb(II): $4.01 \AA, \mathrm{Cu}(\mathrm{II}): 4.19 \AA$, and $\mathrm{Cd}(\mathrm{II}): 4.26 \AA$ ), but not with that of the ionic radius, which correspond to $1.33 \AA$, $0.72 \AA$, and $0.97 \AA$ for $\mathrm{Pb}(\mathrm{II}), \mathrm{Cu}(\mathrm{II})$, and $\mathrm{Cd}(\mathrm{II})$, respectively. Therefore, the metals surrounded by water molecules (i.e., hydrated form), not in the isolated forms, appear to participate in the actual adsorption processes. Overall, our explanation is supported by Baker [27], who suggested ion exchange and physical movement through diffusion as 


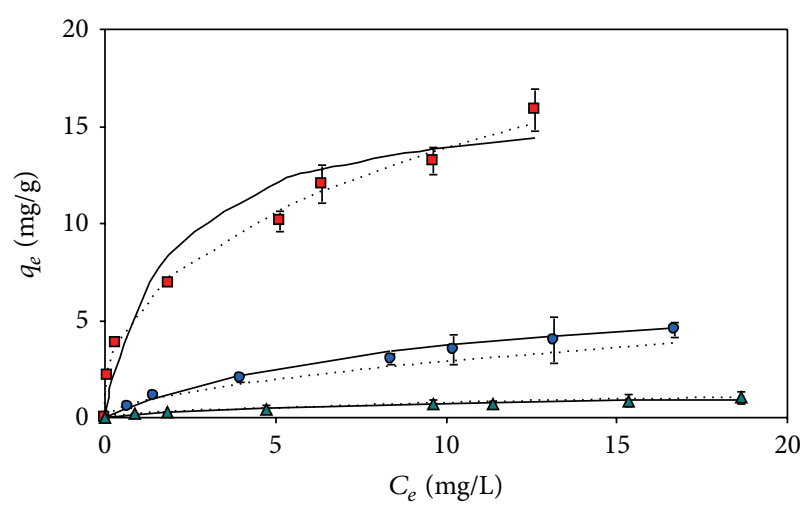

(a)

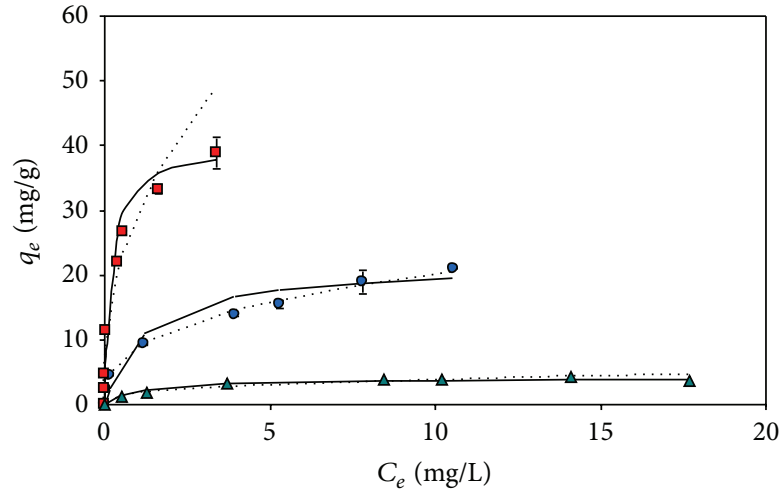

(b)

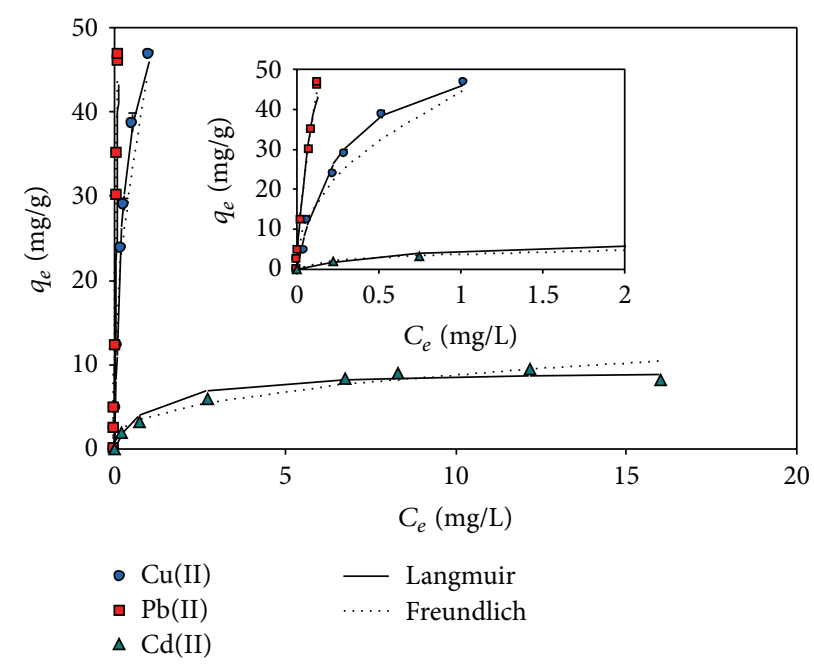

(c)

Figure 4: Adsorption isotherms of $\mathrm{Cu}(\mathrm{II}), \mathrm{Pb}(\mathrm{II})$, and $\mathrm{Cd}(\mathrm{II})$ on magnetic $\mathrm{GO}$ at $\mathrm{pH} 4.0$ (a), 6.0 (b), and 7.0 (c) under the single-metal systems.

the major mechanisms for the adsorption of nickel(II) and copper(II) on silicate minerals.

The relative difference (or the relative ratio) of the $q_{\max }$ values between $\mathrm{Pb}(\mathrm{II})$ and $\mathrm{Cu}(\mathrm{II})$ was greater at a lower $\mathrm{pH}$, at which negatively charged surface sites are more depleted and the competition between the metals and hydrogen ions (and/or sodium ions) becomes greater for available adsorption sites. $\mathrm{Pb}$ (II) exhibited the highest adsorption affinity (i.e., $K_{L}$ ) among the three metals, although $\mathrm{Cu}(\mathrm{II})$ and $\mathrm{Cd}(\mathrm{II})$ were not discriminated in the $K_{L}$ values at $\mathrm{pH} 4.0$ and 6.0.

3.4. Competitive Adsorption Isotherms on Magnetic GO at Different $p H$. The Langmuir isotherm model was applied to the adsorption onto the magnetic GO for multimetal systems containing the three metals, and the calculated isotherm parameters were compared with those of the singlemetal systems (Table 1; Figure 5). Similar approaches have been frequently used in many prior studies to evaluate the competition adsorption of metals [18, 28-31].

In this study, the total adsorption was generally higher for the multimetal systems than for the single-metal systems, while the adsorption of the individual metal was diminished when the three metals were present together. Among the three metals, the greatest decrease (or antagonistic effect) was found for $\mathrm{Pb}$ (II) adsorption at $\mathrm{pH} 7.0$ ( $\sim 7 \%$ reduction). One exception was $\mathrm{Cd}(\mathrm{II})$ adsorption at $\mathrm{pH} 4.0$ and 6.0, showing enhanced adsorption (Figure 5). The decreased adsorption suggests that there is competition between the three metals for the same adsorption sites. Our results agreed with other previous studies reporting the antagonistic effects on multimetal adsorption [23, 25, 31]. In our multimetal systems, $\mathrm{Pb}(\mathrm{II})$ still had the highest maximum adsorption capacity on the magnetic GO at $\mathrm{pH} 4.0$ and 6.0. At pH 7.0, however, $\mathrm{Cu}$ (II) exhibited a slightly higher adsorption level than $\mathrm{Pb}$ (II). These results indicate that the preference of the magnetic GO surfaces for metals may depend on the solution $\mathrm{pH}$, probably resulting from variable surface characteristics with $\mathrm{pH}$. The $q_{\max }$ values of $\mathrm{Pb}(\mathrm{II})$ and $\mathrm{Cu}(\mathrm{II})$ were lower for the multiversus single-metal systems independent of the $\mathrm{pH}$, while $\mathrm{Cd}(\mathrm{II})$ adsorption was dependent on the $\mathrm{pH}$. For example, when the adsorption changed from the single-metal to the multimetal systems at $\mathrm{pH} 6.0$, the maximum adsorption 
TABLE 1: Isotherm model parameters of the metal adsorption on the magnetic GO.

\begin{tabular}{|c|c|c|c|c|c|c|c|c|}
\hline \multirow{2}{*}{ System } & \multirow{2}{*}{ Metals } & \multirow{2}{*}{$\mathrm{pH}$} & \multicolumn{3}{|c|}{ Langmuir } & \multicolumn{3}{|c|}{ Freundlich } \\
\hline & & & $q_{\max }^{\mathrm{a}}$ & $k_{L}^{\mathrm{b}}$ & $R^{2}$ & $k_{F}{ }^{c}$ & $1 / n^{\mathrm{d}}$ & $R^{2}$ \\
\hline \multirow{9}{*}{ Single metal } & $\mathrm{Cu}(\mathrm{II})$ & \multirow{3}{*}{4.0} & $6.24 \pm 0.21^{\mathrm{e}}$ & $0.13 \pm 0.01^{\mathrm{e}}$ & 0.998 & $0.96 \pm 0.08^{\mathrm{e}}$ & $0.55 \pm 0.03^{\mathrm{e}}$ & 0.992 \\
\hline & $\mathrm{Pb}(\mathrm{II})$ & & $15.48 \pm 0.95$ & $0.63 \pm 0.17$ & 0.981 & $5.91 \pm 0.29$ & $0.37 \pm 0.02$ & 0.991 \\
\hline & $\mathrm{Cd}(\mathrm{II})$ & & $1.28 \pm 0.03$ & $0.14 \pm 0.01$ & 0.999 & $0.21 \pm 0.02$ & $0.52 \pm 0.04$ & 0.985 \\
\hline & $\mathrm{Cu}(\mathrm{II})$ & \multirow{3}{*}{6.0} & $23.09 \pm 1.45$ & $0.59 \pm 0.14$ & 0.987 & $8.59 \pm 0.42$ & $0.39 \pm 0.03$ & 0.993 \\
\hline & $\mathrm{Pb}(\mathrm{II})$ & & $38.50 \pm 3.16$ & $4.62 \pm 1.72$ & 0.963 & $27.97 \pm 1.28$ & $0.31 \pm 0.04$ & 0.967 \\
\hline & Cd(II) & & $4.41 \pm 0.19$ & $0.64 \pm 0.12$ & 0.981 & $1.89 \pm 0.29$ & $0.29 \pm 0.07$ & 0.856 \\
\hline & $\mathrm{Cu}(\mathrm{II})$ & \multirow{3}{*}{7.0} & $59.44 \pm 3.64$ & $3.47 \pm 0.54$ & 0.991 & $48.43 \pm 1.91$ & $0.46 \pm 0.04$ & 0.982 \\
\hline & $\mathrm{Pb}(\mathrm{II})$ & & $81.49 \pm 9.94$ & $8.41 \pm 1.97$ & 0.992 & $151.17 \pm 31.26$ & $0.63 \pm 0.09$ & 0.96 \\
\hline & $\mathrm{Cd}(\mathrm{II})$ & & $9.92 \pm 0.55$ & $0.69 \pm 0.18$ & 0.974 & $4.18 \pm 0.59$ & $0.31 \pm 0.06$ & 0.899 \\
\hline \multirow{9}{*}{ Multimetal } & $\mathrm{Cu}(\mathrm{II})$ & \multirow{3}{*}{4.0} & $4.33 \pm 0.08$ & $0.16 \pm 0.01$ & 0.999 & $0.77 \pm 0.10$ & $0.53 \pm 0.05$ & 0.977 \\
\hline & $\mathrm{Pb}(\mathrm{II})$ & & $10.27 \pm 0.72$ & $0.73 \pm 0.25$ & 0.967 & $4.41 \pm 0.39$ & $0.32 \pm 0.04$ & 0.964 \\
\hline & $\mathrm{Cd}(\mathrm{II})$ & & $4.59 \pm 0.15$ & $0.11 \pm 0.01$ & 0.999 & $0.58 \pm 0.07$ & $0.60 \pm 0.05$ & 0.984 \\
\hline & $\mathrm{Cu}(\mathrm{II})$ & \multirow{3}{*}{6.0} & $18.37 \pm 1.07$ & $1.36 \pm 0.44$ & 0.975 & $9.36 \pm 0.87$ & $0.30 \pm 0.05$ & 0.945 \\
\hline & $\mathrm{Pb}(\mathrm{II})$ & & $27.71 \pm 1.19$ & $7.05 \pm 2.00$ & 0.980 & $20.45 \pm 1.18$ & $0.22 \pm 0.04$ & 0.942 \\
\hline & $\mathrm{Cd}(\mathrm{II})$ & & $5.34 \pm 0.21$ & $0.24 \pm 0.03$ & 0.996 & $1.26 \pm 0.08$ & $0.47 \pm 0.03$ & 0.992 \\
\hline & $\mathrm{Cu}(\mathrm{II})$ & \multirow{3}{*}{7.0} & $46.77 \pm 0.96$ & $4.04 \pm 0.26$ & 0.998 & $36.13 \pm 2.07$ & $0.39 \pm 0.06$ & 0.951 \\
\hline & $\mathrm{Pb}(\mathrm{II})$ & & $43.03 \pm 4.83$ & $64.84 \pm 33.86$ & 0.911 & $50.63 \pm 2.07$ & $0.17 \pm 0.02$ & 0.981 \\
\hline & $\mathrm{Cd}(\mathrm{II})$ & & $6.78 \pm 0.32$ & $0.98 \pm 0.24$ & 0.976 & $3.12 \pm 0.21$ & $0.31 \pm 0.03$ & 0.975 \\
\hline
\end{tabular}

${ }^{\mathrm{a}}$ Maximum adsorption capacity estimated by Langmuir isotherm model $\left(\mathrm{mg} \mathrm{g}^{-1}\right)$.

${ }^{\mathrm{b}}$ Adsorption affinity estimated by Langmuir isotherm model $\left(\mathrm{L} \mathrm{mg}^{-1}\right)$.

${ }^{c}$ Freundlich model capacity $\left((\mathrm{mg} / \mathrm{g})(\mathrm{L} / \mathrm{mg})^{1 / n}\right)$.

${ }^{\mathrm{d}}$ Freundlich model site heterogeneity factor (dimensionless).

${ }^{\mathrm{e}}$ Standard errors.

TABle 2: Comparison of $\mathrm{Cu}(\mathrm{II}), \mathrm{Pb}(\mathrm{II})$, and $\mathrm{Cd}(\mathrm{II})$ adsorption capacities of this study with other recent reports using magnetic GO.

\begin{tabular}{|c|c|c|c|c|}
\hline Sorbents & Environmental conditions & Metals & $Q_{\max }(\mathrm{mg} / \mathrm{g})$ & References \\
\hline $\mathrm{GO} / \mathrm{Fe}_{3} \mathrm{O}_{4}$ & $\mathrm{pH}=5.3, T=20^{\circ} \mathrm{C}$ & $\mathrm{Cu}(\mathrm{II})$ & 18.3 & Li et al. [3] \\
\hline \multirow{2}{*}{$\mathrm{GO} /$ silica $/ \mathrm{Fe}_{3} \mathrm{O}_{4}$} & \multirow{2}{*}{$\mathrm{pH}=7.1, T=25^{\circ} \mathrm{C}$} & $\mathrm{Pb}(\mathrm{II})$ & 333.3 & \multirow{2}{*}{ Wang et al. [9] } \\
\hline & & $\mathrm{Cd}(\mathrm{II})$ & 166.7 & \\
\hline $\mathrm{GO} / \mathrm{Fe}_{3} \mathrm{O}_{4} /$ sulfanilic acid & $\mathrm{pH}=6.0, T=25^{\circ} \mathrm{C}$ & $\mathrm{Cd}(\mathrm{II})$ & 55.4 & Hu et al. [7] \\
\hline GO-MnFe ${ }_{2} \mathrm{O}_{4}$ & $\mathrm{pH}=5.0, T=25^{\circ} \mathrm{C}$ & $\mathrm{Pb}(\mathrm{II})$ & 673 & Kumar et al. [11] \\
\hline \multirow{3}{*}{ Reduced $\mathrm{GO} / \mathrm{CoFe}_{2} \mathrm{O}_{4}$} & $\mathrm{pH}=5.3, T=25^{\circ} \mathrm{C}$ & & 299.4 & \multirow{3}{*}{ Zhang et al. [12] } \\
\hline & $\mathrm{pH}=5.3, T=35^{\circ} \mathrm{C}$ & $\mathrm{Pb}(\mathrm{II})$ & 274.7 & \\
\hline & $\mathrm{pH}=5.3, T=45^{\circ} \mathrm{C}$ & & 253.2 & \\
\hline \multirow{2}{*}{ GO/Mn-doped Fe(III) oxide } & \multirow{2}{*}{$\mathrm{pH}=5.0, T=25^{\circ} \mathrm{C}$} & $\mathrm{Cd}(\mathrm{II})$ & 87.2 & \multirow{2}{*}{ Nandi et al. [8] } \\
\hline & & $\mathrm{Cu}(\mathrm{II})$ & 129.7 & \\
\hline \multirow{2}{*}{$\mathrm{GO} / \mathrm{Fe}_{3} \mathrm{O}_{4} /$ sulfanilic acid } & $\mathrm{pH}=5.0, T=20^{\circ} \mathrm{C}$ & \multirow{2}{*}{$\mathrm{Cu}(\mathrm{II})$} & 50.7 & \multirow{2}{*}{ Hu et al. [6] } \\
\hline & $\mathrm{pH}=5.0, T=30^{\circ} \mathrm{C}$ & & 56.9 & \\
\hline \multirow{3}{*}{$\mathrm{GO} / \mathrm{Fe}_{3} \mathrm{O}_{4}$} & \multirow{3}{*}{$\mathrm{pH}=6.0, T=20^{\circ} \mathrm{C}$} & $\mathrm{Cu}(\mathrm{II})$ & 23.1 & \multirow{3}{*}{ This study } \\
\hline & & $\mathrm{Pb}(\mathrm{II})$ & 38.5 & \\
\hline & & $\mathrm{Cd}(\mathrm{II})$ & 4.4 & \\
\hline
\end{tabular}

levels dropped by $\sim 20 \%$ from $23.1 \pm 1.5$ to $18.4 \pm 1.1 \mathrm{mg} \mathrm{g}^{-1}$ for $\mathrm{Cu}(\mathrm{II})$ and by $\sim 28 \%$ from $38.5 \pm 3.2$ to $27.7 \pm 1.2 \mathrm{mg} \mathrm{g}^{-1}$ for $\mathrm{Pb}(\mathrm{II})$. For $\mathrm{Cd}(\mathrm{II})$, however, they increased by $\sim 21 \%$ from $4.4 \pm 0.2$ to $5.3 \pm 0.2 \mathrm{mg} \mathrm{g}^{-1}$ (Table 1 ). The enhanced adsorption capacity of $\mathrm{Cd}(\mathrm{II})$ was found at $\mathrm{pH} 4.0$ and 6.0 but not at $\mathrm{pH}$ 7.0. Therefore, there seems to be no consistent trend for the competitive adsorption with either $\mathrm{pH}$ or the type of the metals for this study.
Our observation of the competitive effects did not agree with those expected from the relative adsorption affinity of each metal that follows in the order of $\mathrm{Pb}(\mathrm{II})>\mathrm{Cu}(\mathrm{II}) \sim$ $\mathrm{Cd}(\mathrm{II})$, assuming that a metal with a higher adsorption affinity would displace others with a lower affinity on adsorbents when the metals compete for the same adsorption sites [18, 31]. Therefore, some other factors than adsorption affinity may be responsible for the competitive adsorption 


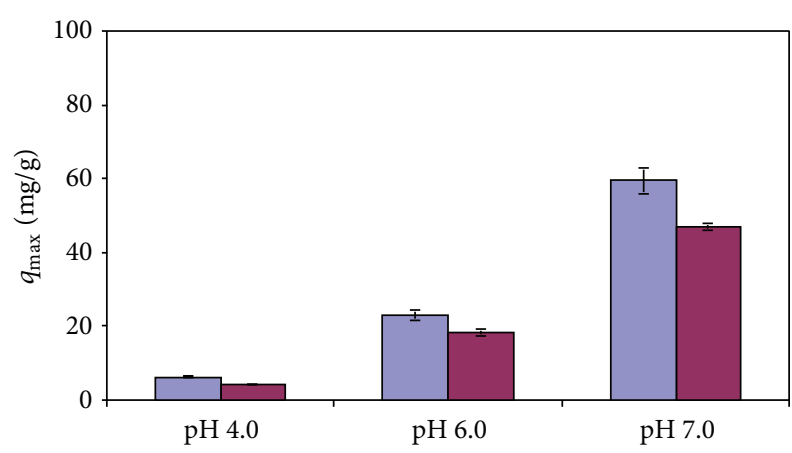

(a)

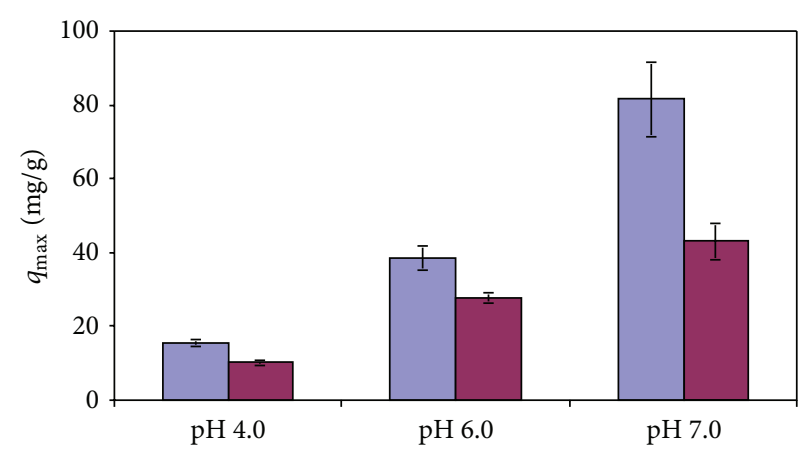

(b)

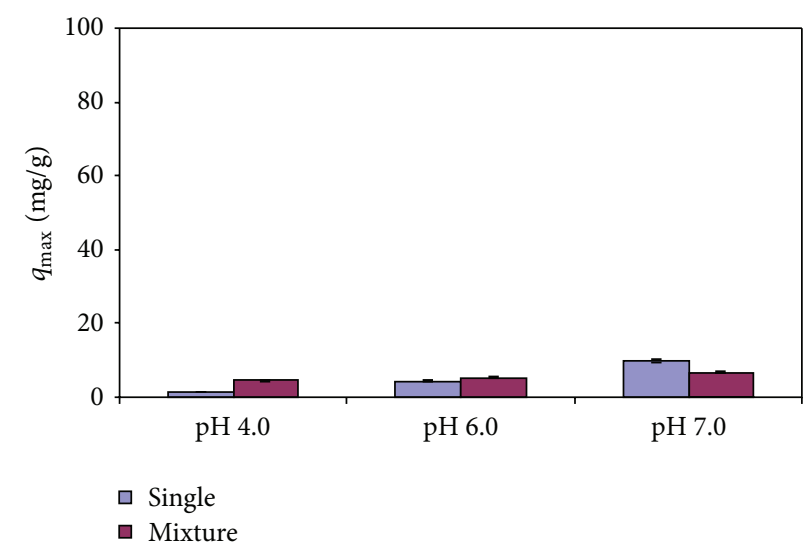

(c)

Figure 5: Comparison of the maximum adsorption capacities of $\mathrm{Cu}(\mathrm{II}), \mathrm{Pb}(\mathrm{II})$, and $\mathrm{Cd}(\mathrm{II})$ on magnetic GO between the single- and multimetal adsorption at pH 4.0 (a), 6.0 (b), and 7.0 (c).

behaviors. In fact, there is no consensus concerning competitive adsorption of metals [26]. Previous literature suggests that antagonistic effects on multimetal adsorption could depend on the type of metals and adsorbents. Sitko et al. [18] have demonstrated that the adsorption rate of $\mathrm{Pb}$ (II) onto GO was the lowest among the metals including $\mathrm{Cu}$ (II) and $\mathrm{Cd}(\mathrm{II})$. This suggests that the low adsorption rate of $\mathrm{Pb}$ (II) may be responsible for the greatest antagonistic effects observed for $\mathrm{Pb}(\mathrm{II})$. Further investigations are warranted to provide concrete evidence.

3.5. Competitive Adsorption of Metals on Different Adsorbents. Competitive adsorption isotherms of the three metals were compared for three different adsorbents at $\mathrm{pH} 7.0$ by examining their Langmuir model parameters (Table 3; Figure S4). Similarly to the magnetic GO, although the total adsorption of the three metals was higher for the multimetal systems, the individual metal adsorption was lower on either PAC or MWCNT compared to the single-metal systems. The degree of the reduction in the $q_{\max }$ values was in the sequence of the magnetic GO > MWCNT > PAC for $\mathrm{Cu}$ (II) and $\mathrm{Pb}(\mathrm{II})$, which have relatively high electronegativity and small hydrated radius. The maximum adsorption levels of $\mathrm{Cu}$ (II) decreased by approximately $21 \%, 12 \%$, and $6 \%$ for the magnetic GO, MWCNT, and PAC, respectively, while, for $\mathrm{Pb}(\mathrm{II})$, they decreased by $\sim 47 \%, \sim 18 \%$, and $\sim 0.2 \%$.
The different competitive adsorption is probably due to the differences in the distributions of available adsorption sites on the surfaces for each metal. Plazinski and Rudzinski [32] have adopted several mathematical isotherm models to demonstrate the effects of surface heterogeneity on the adsorption of heavy metals based on a premise that the surface sites are not energetically and chemically uniform. In this context, the magnetic GO surfaces exhibiting the highest reduction for the multimetal systems are likely to be the most uniform with respect to the active sites for $\mathrm{Cu}$ (II) and $\mathrm{Pb}(\mathrm{II})$. In contrast, the adsorption sites of PAC can be considered to be more heterogeneously distributed with the least pronounced antagonistic effects. More accessible sites for metals in small pores of PAC could contribute to the least antagonistic effects on the competitive adsorption among the three adsorbents [33]. Meanwhile, the same trend with the adsorbents was not found for Cd(II), in which $32 \%, 23 \%$, and $39 \%$ decreases were shown for the magnetic GO, MWCNT, and PAC, respectively. The different competitive adsorption of Cd(II) could relate to such properties of the metal as the largest hydrated radius and the lowest electronegativity, which needs further investigations.

3.6. Effects of Fulvic Acid on Metal Adsorption. Effects of the presence of aquatic fulvic acid on the metal adsorption were examined for the different adsorbents (Table S1). DOC 
TABLE 3: Isotherm model parameters of the metal adsorption on PAC and MWCNT at pH 7.0.

\begin{tabular}{|c|c|c|c|c|c|c|c|c|}
\hline \multirow{2}{*}{ Adsorbents } & \multirow{2}{*}{ Systems } & \multirow{2}{*}{ Metals } & \multicolumn{3}{|c|}{ Langmuir } & \multicolumn{3}{|c|}{ Freundlich } \\
\hline & & & $q_{\max }{ }^{\mathrm{a}}$ & $k_{L}^{\mathrm{b}}$ & $R^{2}$ & $k_{F}{ }^{c}$ & $1 / n^{\mathrm{d}}$ & $R^{2}$ \\
\hline \multirow{6}{*}{ PAC } & \multirow{3}{*}{ Single metal } & $\mathrm{Cu}(\mathrm{II})$ & $34.72 \pm 1.47^{\mathrm{e}}$ & $0.94 \pm 0.13^{\mathrm{e}}$ & 0.993 & $15.54 \pm 1.54^{\mathrm{e}}$ & $0.40 \pm 0.07^{\mathrm{e}}$ & 0.931 \\
\hline & & $\mathrm{Pb}(\mathrm{II})$ & $35.15 \pm 1.15$ & $1.30 \pm 0.14$ & 0.995 & $17.04 \pm 1.60$ & $0.39 \pm 0.07$ & 0.925 \\
\hline & & $\mathrm{Cd}(\mathrm{II})$ & $11.23 \pm 0.38$ & $0.11 \pm 0.01$ & 0.999 & $1.40 \pm 0.11$ & $0.60 \pm 0.03$ & 0.994 \\
\hline & \multirow{3}{*}{ Multimetal } & $\mathrm{Cu}(\mathrm{II})$ & $32.79 \pm 0.76$ & $0.73 \pm 0.05$ & 0.998 & $12.93 \pm 0.99$ & $0.44 \pm 0.05$ & 0.970 \\
\hline & & $\mathrm{Pb}(\mathrm{II})$ & $35.08 \pm 0.38$ & $0.617 \pm 0.02$ & 0.999 & $12.69 \pm 0.98$ & $0.46 \pm 0.05$ & 0.972 \\
\hline & & $\mathrm{Cd}(\mathrm{II})$ & $6.84 \pm 0.20$ & $0.10 \pm 0.01$ & 0.999 & $0.85 \pm 0.09$ & $0.595 \pm 0.04$ & 0.988 \\
\hline \multirow{6}{*}{ MWCNT } & \multirow{3}{*}{ Single metal } & $\mathrm{Cu}(\mathrm{II})$ & $41.42 \pm 0.58$ & $0.72 \pm 0.03$ & 0.999 & $17.49 \pm 0.98$ & $0.41 \pm 0.04$ & 0.988 \\
\hline & & $\mathrm{Pb}(\mathrm{II})$ & $59.08 \pm 0.37$ & $1.22 \pm 0.02$ & 0.999 & $30.95 \pm 0.96$ & $0.57 \pm 0.05$ & 0.983 \\
\hline & & $\mathrm{Cd}(\mathrm{II})$ & $23.07 \pm 0.97$ & $0.13 \pm 0.01$ & 0.998 & $3.34 \pm 0.45$ & $0.60 \pm 0.06$ & 0.976 \\
\hline & \multirow{3}{*}{ Multimetal } & $\mathrm{Cu}(\mathrm{II})$ & $36.53 \pm 2.63$ & $1.13 \pm 0.33$ & 0.985 & $19.11 \pm 0.54$ & $0.32 \pm 0.02$ & 0.994 \\
\hline & & $\mathrm{Pb}(\mathrm{II})$ & $48.21 \pm 2.00$ & $0.36 \pm 0.03$ & 0.998 & $12.53 \pm 0.57$ & $0.58 \pm 0.03$ & 0.993 \\
\hline & & $\mathrm{Cd}(\mathrm{II})$ & $17.86 \pm 0.56$ & $0.11 \pm 0.01$ & 0.999 & $2.26 \pm 0.27$ & $0.62 \pm 0.05$ & 0.983 \\
\hline
\end{tabular}

${ }^{a}$ Maximum adsorption capacity estimated by Langmuir isotherm model $\left(\mathrm{mg} \mathrm{g}^{-1}\right)$.

${ }^{\mathrm{b}}$ Adsorption affinity estimated by Langmuir isotherm model $\left(\mathrm{L} \mathrm{mg}^{-1}\right)$.

${ }^{\mathrm{c}}$ Freundlich model capacity $\left((\mathrm{mg} / \mathrm{g})(\mathrm{L} / \mathrm{mg})^{1 / n}\right)$.

${ }^{\mathrm{d}}$ Freundlich model site heterogeneity factor (dimensionless).

${ }^{\mathrm{e}}$ Standard errors.

measurements of the residual SRFA in solution after adsorption indicate that SRFA was adsorbed by approximately $90 \%$, $80 \%$, and $50 \%$ onto the magnetic GO, PAC, and MWCNT, respectively, for this study under a particular environmental condition. The presence of humic substances (HS) can affect metal adsorption behavior by modifying the surface characteristics of adsorbents and/or by forming complexes with dissolved metals in solution. Previous studies have shown that the adsorption of metals onto adsorbents can be enhanced by the presence of $\mathrm{HS}$ at relatively low $\mathrm{pH}$ mainly due to strong complexation between the negatively charged HS adsorbed on surfaces and the metals in solution [34]. This effect tends to be more evident for the $\mathrm{pH}$ range lower than the $\mathrm{pH}_{\mathrm{ZPC}}$ of adsorbents. Meanwhile, dissolved HS also play roles in the metal adsorption, competing with active surface sites for complexation with metals. This competition effect is likely to be more pronounced for the $\mathrm{pH}$ range higher than the $\mathrm{pH}_{\mathrm{ZPC}}$ of adsorbents, at which the surfaces of adsorbents are net negatively charged similarly to $\mathrm{HS}[3,34]$. Because the concentration of the residual SRFA after adsorption was higher in the order of MWCNT $>$ PAC > magnetic GO for this study, the competition effects of the residual SRFA on metal complexation with surfaces, if any, would be greater in the same order. For a detailed investigation, an evaluation index, $\alpha$, was introduced to qualitatively track the SRFA-induced changes in the adsorption affinity of metals as a function of the initial metal concentrations. Here, $\alpha$ was calculated based on the following equation:

$$
\alpha=\frac{q_{e, \mathrm{SRFA}} / C_{e, \mathrm{SRFA}}}{q_{e} / C_{e}},
$$

where $\alpha$ is the evaluation index for SRFA effects on metal adsorption affinity; $q_{e \text {,SRFA }}$ and $q_{e}$ are the equilibrium adsorption capacities in the presence and the absence of SRFA, respectively. $C_{e, \mathrm{SRFA}}$ and $C_{e}$ are the equilibrium concentrations of metals in solution.
The evaluation index was plotted against the initial metal concentrations in Figure 6. The index was mostly lower than the unity, varying from 0.70 to 0.93 for $\mathrm{Cu}$ (II) with the mean value of $0.87 \pm 0.13$, from 0.77 to 0.95 for $\mathrm{Pb}$ (II) with $0.88 \pm 0.07$, and from 0.66 to 1.04 for Cd(II) with $0.91 \pm 0.09$. These results indicate that the presence of SRFA lowered the metal adsorption on all the adsorbents, and they suggest that the residual SRFA had greater effects on the overall metal adsorption than the adsorbed SRFA. The lowest value $(0.76 \pm 0.17)$ of the index was found for $\mathrm{Cu}(\mathrm{II})$ adsorption onto MWCNT, which was statistically distinguished from the metal adsorption onto the other two adsorbents (ANOVA $P<0.05$ ), probably resulting from the high concentration of the residual SRFA. Such a significant difference in the index among the three adsorbents, however, was not found for the other two metals (ANOVA $P>0.05$ ). This result may be attributed to the much higher complexation capability of SRFA for $\mathrm{Cu}$ (II) compared to $\mathrm{Pb}$ (II) and $\mathrm{Cd}$ (II) [35]. Our results demonstrate that the effects of HS on metal adsorption could depend on the HS concentration in aqueous phase, which varies with solution $\mathrm{pH}$ and the adsorbents, as well as on the type of the metal.

\section{Conclusions}

Magnetic GO was successfully synthesized by a simple ultrasonification method using graphite oxide and $\mathrm{Fe}_{3} \mathrm{O}_{4}$ nanoparticles. The adsorption of $\mathrm{Cu}(\mathrm{II}), \mathrm{Pb}(\mathrm{II})$, and $\mathrm{Cd}(\mathrm{II})$ all increased with a higher $\mathrm{pH}$, with sharp changes at the $\mathrm{pH}$ values around the $\mathrm{pH}_{\mathrm{ZPC}}$ of each adsorbent. The equilibrium adsorption was better described by the Langmuir isotherm model than the Freundlich model, indicating that monolayer adsorption processes can explain the metal adsorption. The $q_{\max }$ values of the metals on the magnetic GO were higher in the order of $\mathrm{Pb}(\mathrm{II})>\mathrm{Cu}(\mathrm{II})>\mathrm{Cd}(\mathrm{II})$. The relative order of the $q_{\max }$ values was consistent with the sequence of 


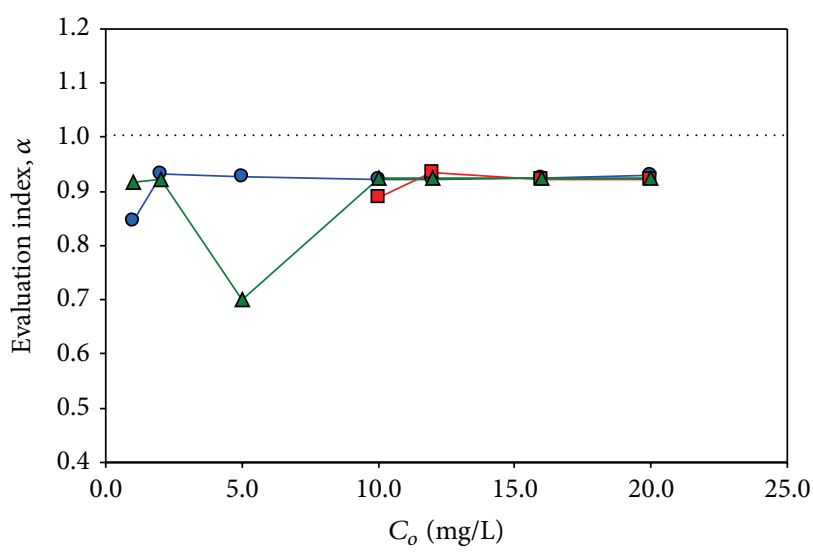

(a)

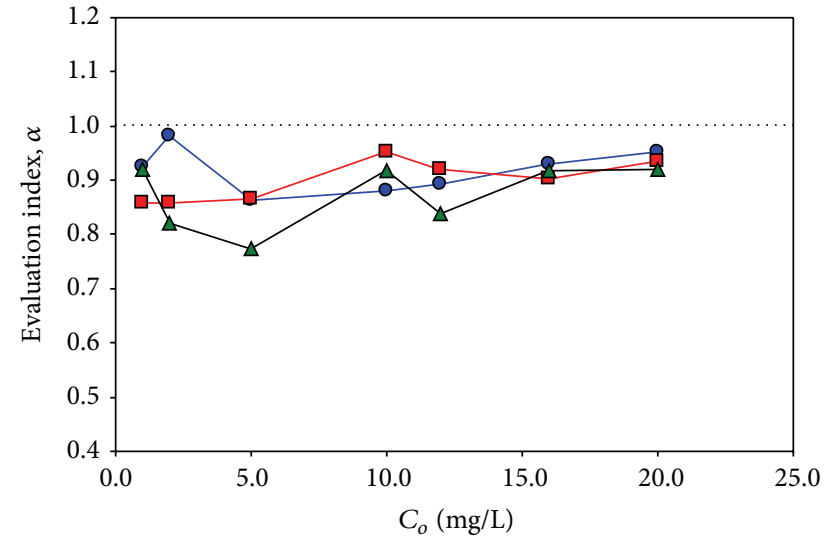

(b)

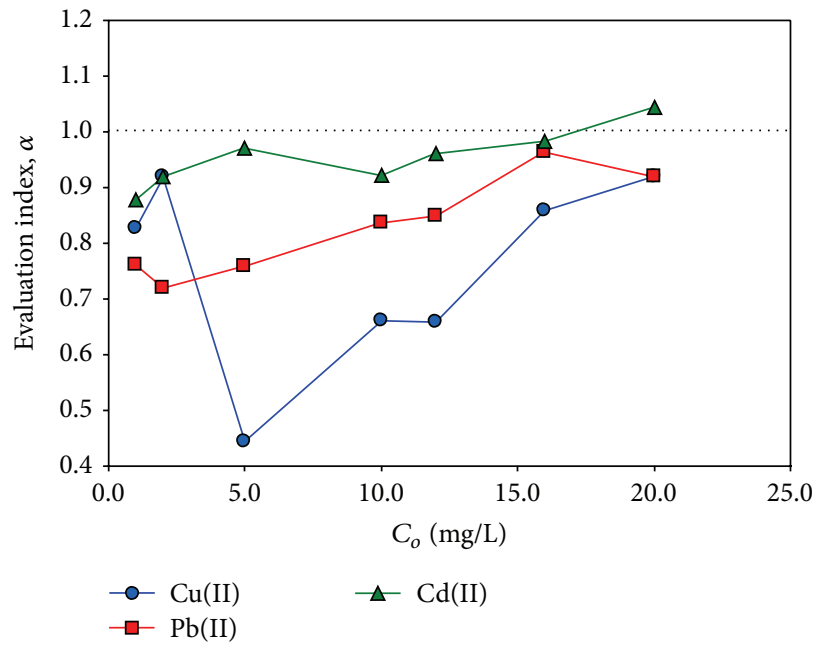

(c)

Figure 6: The evaluation index (a) for SRFA effects on metal adsorption on magnetic GO (a), PAC (b), and MWCNT (c) as a function of the initial metal concentrations $\left(C_{o}\right)$. The first three data points of $\mathrm{Pb}(\mathrm{II})$ on the magnetic $\mathrm{GO}$ were neglected because of the extremely low equilibrium concentrations $\left(C_{e}\right)$.

the electronegativity and the hydrated radius of the metals. The adsorption of the individual metal was mostly reduced when other metals coexisted, indicating that the competition among the metals exists for the adsorption sites. However, the trend of the reduction with solution $\mathrm{pH}$ and the degree were different for each metal. Comparison of the $q_{\max }$ values between the single- and multimetal systems of $\mathrm{Cu}(\mathrm{II})$ and $\mathrm{Pb}$ (II) revealed that the competitive adsorption was greater in the order of the magnetic GO > MWCNT > PAC. For all the three adsorbents, the presence of SRFA decreased the adsorption affinities of the metals, suggesting that dissolved HS play a greater role than adsorbed HS in metal adsorption by competing with active surface sites for the complexation with metals.

\section{Conflict of Interests}

The authors have no commercial, financial, or other relationship related to the subject of this work that would constitute.

\section{Acknowledgment}

This study was supported by a National Research Foundation of Korea Grant funded by the Korean Government (MEST) (NRF-2010-0021086).

\section{References}

[1] F. Fu and Q. Wang, "Removal of heavy metal ions from wastewaters: a review," Journal of Environmental Management, vol. 92, no. 3, pp. 407-418, 2011.

[2] G. P. Rao, C. Lu, and F. Su, "Sorption of divalent metal ions from aqueous solution by carbon nanotubes: a review," Separation and Purification Technology, vol. 58, no. 1, pp. 224-231, 2007.

[3] J. Li, S. Zhang, C. Chen et al., "Removal of $\mathrm{Cu}(\mathrm{II})$ and fulvic acid by graphene oxide nanosheets decorated with $\mathrm{Fe}_{3} \mathrm{O}_{4}$ nanoparticles," ACS Applied Materials and Interfaces, vol. 4, no. 9, pp. 4991-5000, 2012.

[4] S. Stankovich, D. A. Dikin, G. H. B. Dommett et al., "Graphenebased composite materials," Nature, vol. 442 , no. 20 , pp. $282-$ 286, 2006. 
[5] G. Xie, P. Xi, H. Liu et al., "A facile chemical method to produce superparamagnetic graphene oxide- $\mathrm{Fe}_{3} \mathrm{O}_{4}$ hybrid composite and its application in the removal of dyes from aqueous solution," Journal of Materials Chemistry, vol. 22, no. 3, pp. 10331039, 2012.

[6] X.-J. Hu, Y.-G. Liu, H. Wang et al., "Removal of $\mathrm{Cu}$ (II) ions from aqueous solution using sulfonated magnetic graphene oxide composite," Separation and Purification Technology, vol. 108, pp. 189-195, 2013.

[7] X.-J. Hu, Y.-G. Liu, G.-M. Zeng et al., "Effects of background electrolytes and ionic strength on enrichment of $\mathrm{Cd}$ (II) ions with magnetic graphene oxide-supported sulfanilic acid," Journal of Colloid and Interface Science, vol. 435, pp. 138-144, 2014.

[8] D. Nandi, T. Basu, S. Debnath, A. K. Ghosh, A. De, and U. C. Ghosh, "Mechanistic insight for the sorption of $\mathrm{Cd}(\mathrm{II})$ and $\mathrm{Cu}$ (II) from aqueous solution on magnetic mn-doped $\mathrm{Fe}$ (III) oxide nanoparticle implanted graphene," Journal of Chemical and Engineering Data, vol. 58, no. 10, pp. 2809-2818, 2013.

[9] Y. Wang, S. Liang, B. Chen, F. Guo, S. Yu, and Y. Tang, "Synergistic removal of $\mathrm{Pb}(\mathrm{II}), \mathrm{Cd}(\mathrm{II})$ and humic acid by $\mathrm{Fe}_{3} \mathrm{O}_{4} @$ mesoporous silica-graphene oxide composites," PLoS ONE, vol. 8, no. 6, Article ID e65634, 2013.

[10] P. Zong, S. Wang, Y. Zhao, H. Wang, H. Pan, and C. He, "Synthesis and application of magnetic graphene/iron oxides composite for the removal of U(VI) from aqueous solutions," Chemical Engineering Journal, vol. 220, pp. 45-52, 2013.

[11] S. Kumar, R. R. Nair, P. B. Pillai, S. N. Gupta, M. A. R. Iyengar, and A. K. Sood, "Grapheneoxide- $\mathrm{MnFe}_{2} \mathrm{O}_{4}$ magnetic nanohybrids for efficient removal of lead and arsenic from water," ACS Applied Materials \& Interfaces, vol. 6, no. 20, pp. 1742617436, 2014

[12] Y. Zhang, L. Yan, W. Xu et al., "Adsorption of $\mathrm{Pb}(\mathrm{II})$ and $\mathrm{Hg}$ (II) from aqueous solution using magnetic $\mathrm{CoFe}_{2} \mathrm{O}_{4}$ reduced graphene oxide," Journal of Molecular Liquids, vol. 191, pp. 177-182, 2014.

[13] H. L. Karlsson, J. Gustafsson, P. Cronholm, and L. Möller, "Sizedependent toxicity of metal oxide particles-a comparison between nano- and micrometer size," Toxicology Letters, vol. 188, no. 2, pp. 112-118, 2009.

[14] J. P. Chen and S. Wu, "Acid/base-treated activated carbons: characterization of functional groups and metal adsorptive properties," Langmuir, vol. 20, no. 6, pp. 2233-2242, 2004.

[15] H. Yan, H. Li, X. Tao et al., "Rapid removal and separation of iron(II) and manganese(II) from micropolluted water using magnetic graphene oxide," ACS Applied Materials \& Interfaces, vol. 6, no. 12, pp. 9871-9880, 2014.

[16] D. C. Marcano, D. V. Kosynkin, J. M. Berlin et al., "Improved synthesis of graphene oxide," ACS Nano, vol. 4, no. 8, pp. 4806$4814,2010$.

[17] $\mathrm{H}$. Wei and E. Wang, " $\mathrm{Fe}_{3} \mathrm{O}_{4}$ magnetic nanoparticles as peroxidase mimetics and their applications in $\mathrm{H}_{2} \mathrm{O}_{2}$ and glucose detection," Analytical Chemistry, vol. 80, no. 6, pp. 2250-2254, 2008.

[18] R. Sitko, E. Turek, B. Zawisza et al., "Adsorption of divalent metal ions from aqueous solutions using graphene oxide," Dalton Transactions, vol. 42, no. 16, pp. 5682-5689, 2013.

[19] L. Ai, C. Zhang, and Z. Chen, "Removal of methylene blue from aqueous solution by a solvothermal-synthesized graphene/ magnetite composite," Journal of Hazardous Materials, vol. 192, no. 3, pp. 1515-1524, 2011.

[20] S. K. Milonjić, M. M. Kopečni, and Z. E. Ilić, "The point of zero charge and adsorption properties of natural magnetite," Journal of Radioanalytical and Nuclear Chemistry, vol. 78, no. 1, pp. 1524, 1983.

[21] G. Zhao, T. Wen, X. Yang et al., "Preconcentration of U(VI) ions on few-layered graphene oxide nanosheets from aqueous solutions," Dalton Transactions, vol. 41, no. 20, pp. 6182-6188, 2012.

[22] H. Kim, M. E. Fortunato, H. Xu, J. H. Bang, and K. S. Suslick, "Carbon microspheres as supercapacitors," The Journal of Physical Chemistry C, vol. 115, no. 42, pp. 20481-20486, 2011.

[23] Y.-H. Li, J. Ding, Z. Luan et al., “Competitive adsorption of $\mathrm{Pb}^{2+}$, $\mathrm{Cu}^{2+}$ and $\mathrm{Cd}^{2+}$ ions from aqueous solutions by multiwalled carbon nanotubes," Carbon, vol. 41, no. 14, pp. 2787-2792, 2003.

[24] S. A. Kosa, G. Al-Zhrani, and M. Abdel Salam, "Removal of heavy metals from aqueous solutions by multi-walled carbon nanotubes modified with 8-hydroxyquinoline," Chemical Engineering Journal, vol. 181-182, pp. 159-168, 2012.

[25] F. Qin, B. Wen, X.-Q. Shan et al., "Mechanisms of competitive adsorption of $\mathrm{Pb}, \mathrm{Cu}$, and $\mathrm{Cd}$ on peat," Environmental Pollution, vol. 144, no. 2, pp. 669-680, 2006.

[26] M. A. Salam, G. Al-Zhrani, and S. A. Kosa, "Simultaneous removal of copper(II), lead(II), zinc(II) and cadmium(II) from aqueous solutions by multi-walled carbon nanotubes," Comptes Rendus Chimie, vol. 15, no. 5, pp. 398-408, 2012.

[27] H. Baker, "Characterization for the interaction of nickel(II) and copper(II) from aqueous solutions with natural silicate minerals," Desalination, vol. 244, no. 1-3, pp. 48-58, 2009.

[28] K. Kadirvelu, J. Goel, and C. Rajagopal, "Sorption of lead, mercury and cadmium ions in multi-component system using carbon aerogel as adsorbent," Journal of Hazardous Materials, vol. 153, no. 1-2, pp. 502-507, 2008.

[29] T. Terdkiatburana, S. Wang, and M. O. Tadé, "Competition and complexation of heavy metal ions and humic acid on zeolitic MCM-22 and activated carbon," Chemical Engineering Journal, vol. 139, no. 3, pp. 437-444, 2008.

[30] Y. Liu, H. Li, and X.-H. Zhu, "Competitive adsorption of $\mathrm{Ag}^{+}$, $\mathrm{Pb}^{2+}, \mathrm{Ni}^{2+}$, and $\mathrm{Cd}^{2+}$ ions on vermiculite," Separation Science and Technology, vol. 45, no. 2, pp. 277-287, 2010.

[31] M. Zhang, "Adsorption study of $\mathrm{Pb}(\mathrm{II}), \mathrm{Cu}(\mathrm{II})$ and $\mathrm{Zn}$ (II) from simulated acid mine drainage using dairy manure compost," Chemical Engineering Journal, vol. 172, no. 1, pp. 361-368, 2011.

[32] W. Plazinski and W. Rudzinski, "Modeling the effect of surface heterogeneity in equilibrium of heavy metal ion biosorption by using the ion exchange model," Environmental Science and Technology, vol. 43, no. 19, pp. 7465-7471, 2009.

[33] A. J. Brooks, H.-N. Lim, and J. E. Kilduff, "Adsorption uptake of synthetic organic chemicals by carbon nanotubes and activated carbons," Nanotechnology, vol. 23, no. 29, Article ID 294008, 2012.

[34] S. Yang, J. Hu, C. Chen, D. Shao, and X. Wang, "Mutual effects of $\mathrm{Pb}(\mathrm{II})$ and humic acid adsorption on multiwalled carbon nanotubes/polyacrylamide composites from aqueous solutions," Environmental Science and Technology, vol. 45, no. 8, pp. 3621-3627, 2011.

[35] P. Chakraborty, I. I. Fasfous, J. Murimboh, and C. L. Chakrabarti, "Simultaneous determination of speciation parameters of $\mathrm{Cu}, \mathrm{Pb}, \mathrm{Cd}$ and $\mathrm{Zn}$ in model solutions of Suwannee River fulvic acid by pseudopolarography," Analytical and Bioanalytical Chemistry, vol. 388, no. 2, pp. 463-474, 2007. 

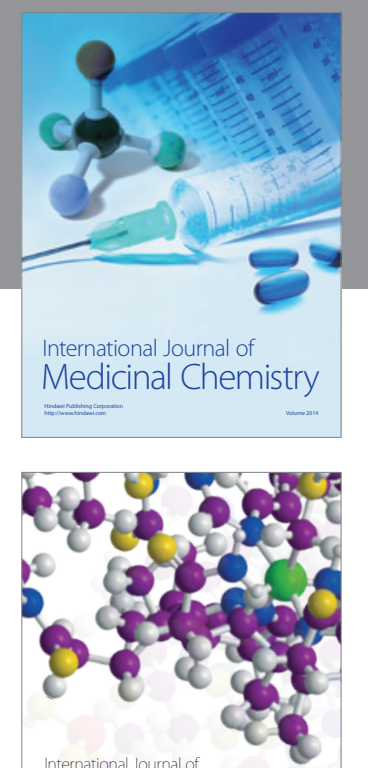

\section{Carbohydrate} Chemistry

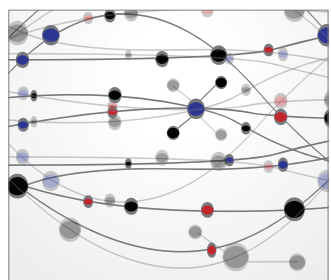

The Scientific World Journal
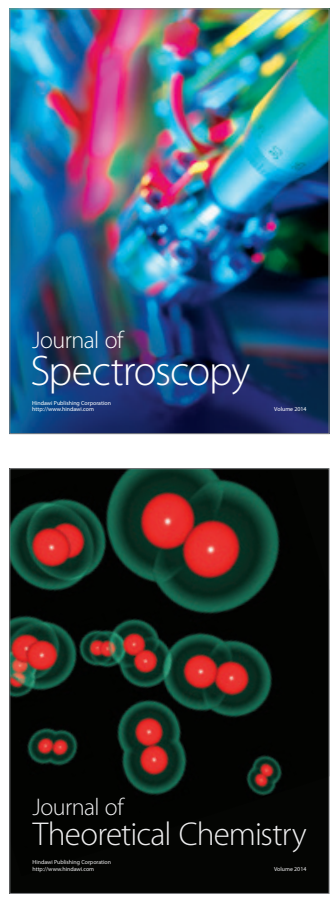
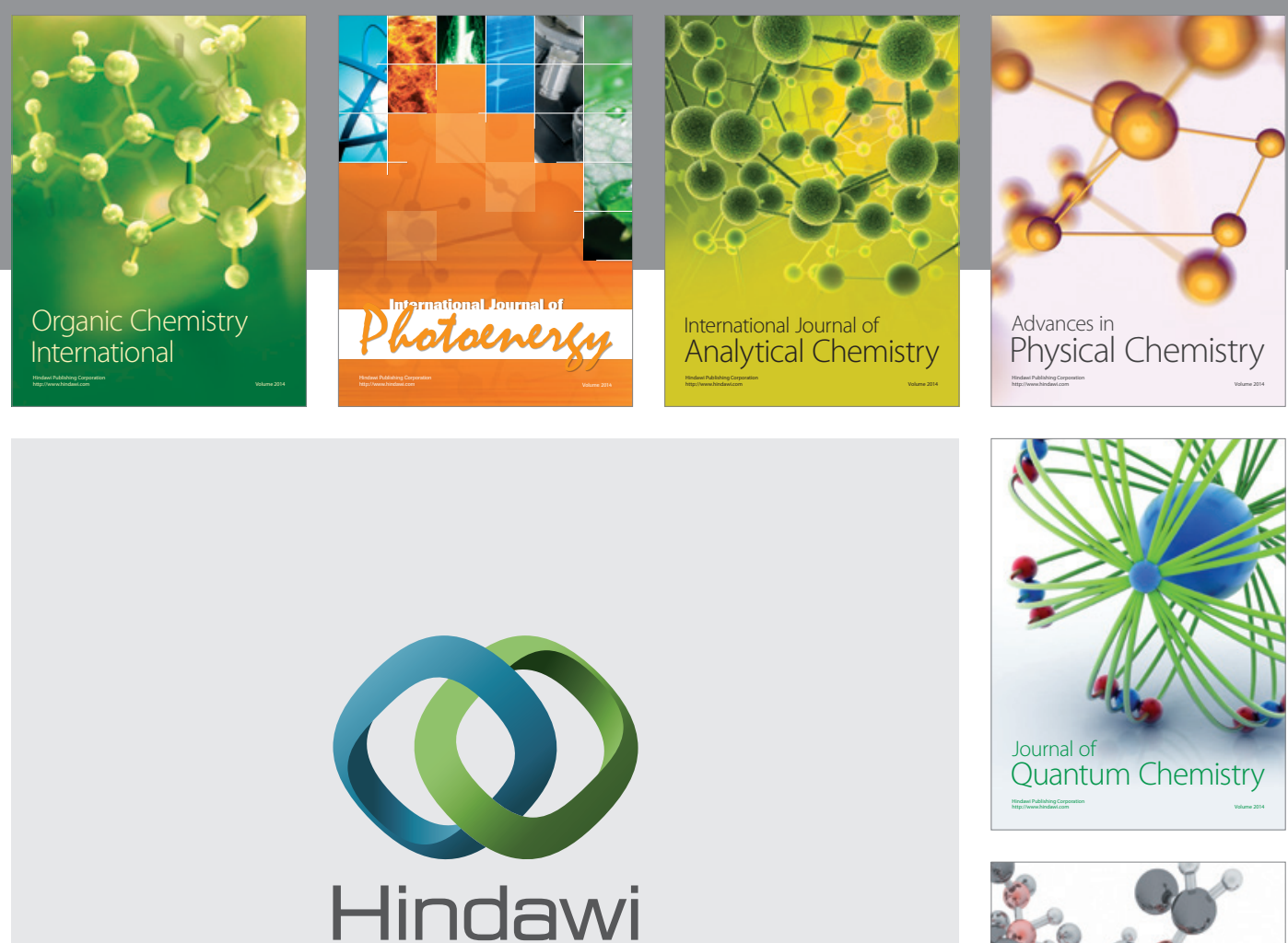

Submit your manuscripts at

http://www.hindawi.com

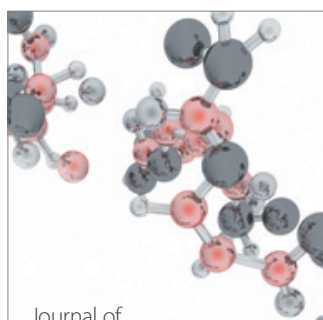

Analytical Methods

in Chemistry

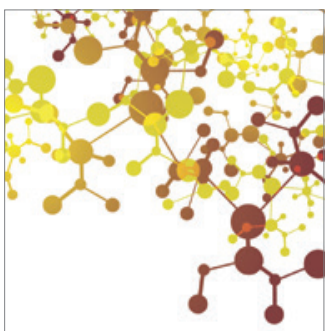

Journal of

Applied Chemistry

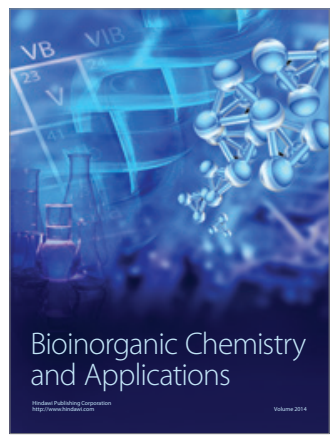

Inorganic Chemistry
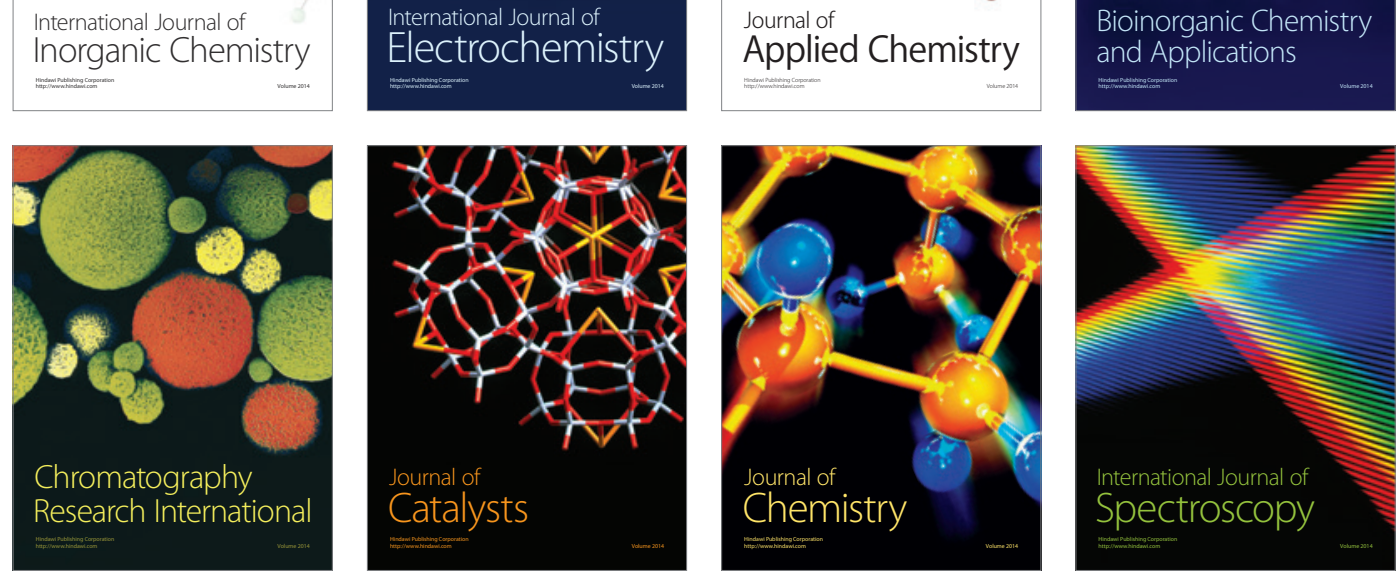